\title{
Chemoselective Reductive Heterocyclization by Controlling the Binomial Architecture of Metal Particles and Acid-Base Properties of the Support
}

\author{
L. Marti, ${ }^{\dagger}$ L. M. Sanchez, ${ }^{\ddagger}$ Maria J. Climent, ${ }^{* \dagger}$ A. Corma, ${ }^{*}{ }^{\dagger}$ S. Iborra, ${ }^{\dagger}$ G. P. Romanelli, ${ }^{\ddagger}$
} and P. Concepcion ${ }^{\dagger}$

†Instituto de Tecnología Química (UPV-CSIC), Universitat Politècnica de València, 46022 Valencia, Spain

${ }^{\ddagger}$ Centro de Investigación y Desarrollo en Ciencias Aplicadas 'Dr. J. J. Ronco’ (CINDECA), Departamento de Química, Universidad Nacional de La Plata,1900 La Plata, Argentina

\section{Supporting Information}

ABSTRACT: 2,1-Benzisoxazoles have been selectively synthesized through reductive heterocyclization of 2-nitroacylarenes using $\mathrm{Pt}$ supported nanoparticles. The reaction involves a cascade process in which the first step is the reduction of the nitro group into<smiles>[R]C(=O)c1ccccc1[N+](=O)[O-]</smiles>

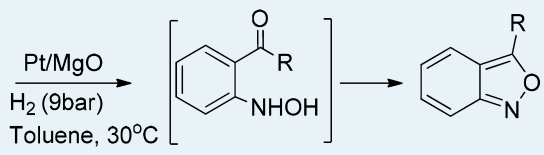
hydroxylamine followed by heterocyclization through the nucleophilic attack of the hydroxylamine group to the carbonyl of the acyl group and further dehydration. The reaction was performed on $\mathrm{Pt} /$ $\mathrm{C}, \mathrm{Pt} / \mathrm{TiO}_{2}$, and $\mathrm{Pt} / \mathrm{MgO}$ using hydrogen as the reducing agent under mild reaction conditions. The results showed that $\mathrm{Pt} /$ $\mathrm{MgO}$ was the most active and selective catalyst. The study of the influence of the crystal size of the metal on the activity and selectivity, combined with the reaction mechanism examined by in situ Fourier transform infrared spectroscopy of the adsorbed reactant, showed that the maximum activity and selectivity to the target compound can be achieved by controlling the architecture of metal particles and acid-base properties of the support. The effect of temperature on selectivity, the stability of the $\mathrm{Pt} / \mathrm{MgO}$ catalyst, and the scope of the reaction have been studied. Finally, reductive heterocyclization using different metals (Pd and $\mathrm{Au}$ ) supported on $\mathrm{MgO}$ has also been performed.

KEYWORDS: reductive heterocyclization, 2,1-benzisoxazole, $\mathrm{Pt} / \mathrm{MgO}$, 2-nitroacylarenes, cascade process

\section{INTRODUCTION}

2,1-Benzisoxazoles (anthranils) are fused heteroaromatic systems that are useful as building blocks for preparing a broad class of compounds with important biological properties and industrial applications. For instance, 2,1-benzisoxazole derivatives are employed in the treatment of some disorders of the central nervous system, for instance, Alzheimer's disease, other forms of dementia, and cerebral infarct. ${ }^{1}$ They are also used as antiplasmodial, antimicrobial, ${ }^{2}$ and anti-inflammatory agents. ${ }^{3}$ Anthranils and their salts can also be used as starting materials to prepare other heterocyclic systems for tranquilizer drugs such as Valium ${ }^{4}$ or acridones (in the production of dyes and pharmaceutical products). ${ }^{5}$

Different approaches can be used to synthesize 2,1benzisoxazoles, for instance, the reaction of substituted nitroarenes and arylacetonitriles in a concentrated strong base alcoholic solution, ${ }^{6}$ and in the presence of silylating agents, ${ }^{7}$ heterocyclization of 2-azido aryl ketones, ${ }^{8}$ and addition of glyoxylate esters to nitrosoarenes catalyzed by Lewis acid. ${ }^{9}$ However, the most common method for preparing 2,1benzisoxazoles involves the reductive heterocyclization of 2 nitroacylbenzene derivatives. This transformation occurs through the partial reduction of the nitro group to the hydroxylamine function followed by heterocyclization through the nucleophilic attack of the hydroxylamine group to the carbonyl of the acyl group and further dehydration ${ }^{10}$ (see Scheme 1).

Scheme 1. Mechanism of the Reductive Heterocyclization of 2-Nitroacylarenes

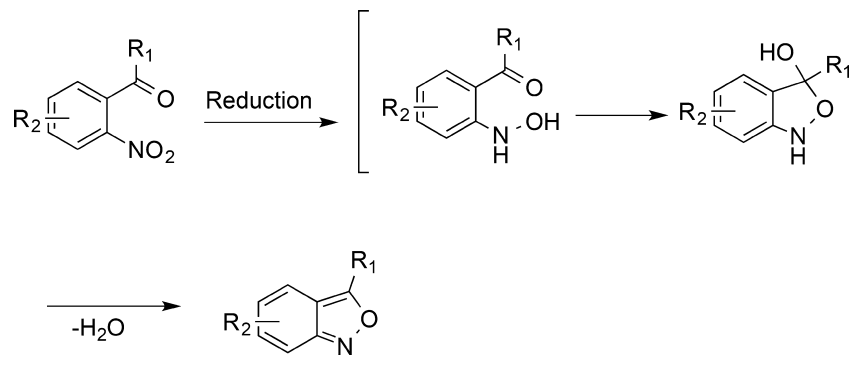

Classically, the reaction is performed using $\mathrm{Sn}$ or $\mathrm{SnCl}_{2}$ in concentrated $\mathrm{HCl},{ }^{10,11}$ although other approaches use $\mathrm{SnCl}_{2}$. $2 \mathrm{H}_{2} \mathrm{O}^{12}$ or indium metal with different additives in water or methanol to promote the reductive heterocyclization of 2nitroacylbenzenes. However, the temperature and concentration of the reducing agent should be controlled because

Received: June 6, 2017

Revised: August 16, 2017

Published: September 26, 2017 
over-reduction of 2,1-benzisoxazole into the corresponding 2aminoacyl compound by reductive cleavage can occur, yielding the corresponding 2,1-benzisoxazoles with low selectivity ${ }^{13}$ (Scheme 2).

Scheme 2. Pathway of the Reduction of 2-Nitroacylarenes<smiles>[R]C(=O)c1ccccc1[N+](=O)[O-]</smiles>

1
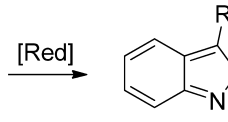

2

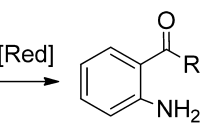

3
In general, through the methods described above, 2,1benzisoxazole derivatives are obtained after long reaction times and with non-reusable catalysts. Therefore, a sustainable route for preparing 2,1-benzisoxazole derivatives involving the use of an active, selective, and reusable heterogeneous catalyst based on metal-supported nanoparticles with hydrogen as the reducing agent would be of interest. However, this route is not easy because catalytic hydrogenation can promote not only the reductive cleavage of 2,1-benzisoxazoles into 2-aminoacylbenzenes but also the complete and fast reduction of the nitro into an amino group and the reduction of the carbonyl group of the nitroacylarene. In fact, in the reports of hydrogenation of 2-nitroacylarene derivatives using $\mathrm{Pt}$ (colloidal Pt solution) $)^{14}$ or $\mathrm{Pd} / \mathrm{C}^{15}$ catalysts, a mixture of 2,1 benzisoxazole and 2-aminoacyl derivative, with low selectivity for the former, is obtained. It appears that to perform successfully the reaction to obtain a high yield and a high selectivity of the 2,1-benzisoxazole, a catalyst that promotes the formation of the hydroxylamine intermediate and the fast nucleophilic attack on the carbonyl group of the acyl group is required, while avoiding the reductive cleavage of the 2,1benzisoxazole.

In the work presented here, we will show that via the control of the binomial architecture of the metal nanoparticles and the nature of the support a nonselective catalyst such as $\mathrm{Pt}$ can be transformed to yield 2,1-benzisoxazoles in excellent yields and selectivities by reductive heterocyclization of 2-nitroacylarenes.

\section{EXPERIMENTAL SECTION}

2-Nitroacylarenes (>99\%), toluene $(\geq 99 \%)$, and dodecane $(\geq 99 \%)$ were purchased from Aldrich. Gold(III) chloride trihydrate (99.9\%), platinum(II) acetylacetonate (97\%), and palladium(II) acetylacetonate (99\%) were purchased from Aldrich. The $\mathrm{MgO}$ sample with a surface area of $670 \mathrm{~m}^{2} \mathrm{~g}^{-1}$ was purchased from NanoScale Materials. $\mathrm{TiO}_{2}$ (P-25, Degussa) and active carbon (Darco KB-B) supports were supplied by Evonik Industries and Aldrich, respectively.

The 0.2 wt $\% \mathrm{Pt} / \mathrm{TiO}_{2}$ sample with a Pt crystal size of $1.5 \mathrm{~nm}$ was prepared by incipient wetness impregnation following a previously reported procedure ${ }^{16}$ and reduced at $450{ }^{\circ} \mathrm{C}$.

$\mathrm{Pt} / \mathrm{MgO}$ samples with different amounts of $\mathrm{Pt}$ were prepared by impregnation of the support with the corresponding amount of a solution of platinum(II) acetylacetonate, in water free toluene $(12.5 \mathrm{~mL})$ that was added to $1 \mathrm{~g}$ of the oxide support. The mixture was stirred for $12 \mathrm{~h}$ at room temperature, and the solvent was removed at reduced pressure and dried overnight under vacuum. The samples were calcined for $3.5 \mathrm{~h}$ at $550{ }^{\circ} \mathrm{C}$ with a $\mathrm{N}_{2}$ flow of $100 \mathrm{~mL} \mathrm{~min}{ }^{-1}$ and activated by calcination at $450{ }^{\circ} \mathrm{C}$ with a $\mathrm{H}_{2}$ flow of $100 \mathrm{~mL} \mathrm{~min}^{-1}$ for $3 \mathrm{~h}$. $\mathrm{Pd} / \mathrm{MgO}$ and $\mathrm{Au} / \mathrm{MgO}$ samples were prepared following the same procedure.
A sample of 0.1 wt \% Pt on $\mathrm{MgO}$ was prepared using a solution of $\mathrm{H}_{2} \mathrm{PtCl}_{6} \cdot 6 \mathrm{H}_{2} \mathrm{O}(2.8 \mathrm{mg})$ in acetone $(25 \mathrm{~mL})$ by impregnation of $1 \mathrm{~g}$ of $\mathrm{MgO}$. The mixture was stirred for $12 \mathrm{~h}$ at room temperature, the solvent removed at reduced pressure, and the mixture dried overnight under vacuum. The samples were calcined for $3.5 \mathrm{~h}$ at $550{ }^{\circ} \mathrm{C}$ with a $\mathrm{N}_{2}$ flow of $100 \mathrm{~mL}$ $\min ^{-1}$ and activated by calcination at $450{ }^{\circ} \mathrm{C}$ with a $\mathrm{H}_{2}$ flow of $100 \mathrm{~mL} \min ^{-1}$ for $3 \mathrm{~h}$. The average mean diameter of metal nanoparticles, measured by high-resolution transmission electron microscopy (HRTEM) images, was $1.2 \mathrm{~nm}$.

A sample with 0.2 wt \% Pt on porous active carbon (Darco KB-B, 100 mesh) was obtained by incipient wetness impregnation with an aqueous solution $(2 \mathrm{~mL})$ containing the desired amount of metal $\left(10.56 \mathrm{mg}\right.$ of $\left.\mathrm{H}_{2} \mathrm{PtCl}_{6} \cdot 6 \mathrm{H}_{2} \mathrm{O}\right)$ to form a thick paste $(2 \mathrm{~g})$. The catalyst paste was mixed thoroughly with a spatula for $10 \mathrm{~min}$. Then, the sample was dried at $100{ }^{\circ} \mathrm{C}$ for $12 \mathrm{~h}$. The final catalyst was activated by reduction in a fix bed reactor with a $\mathrm{H}_{2}$ flow of $100 \mathrm{~mL} / \mathrm{min}$ at $450{ }^{\circ} \mathrm{C}$ for $3 \mathrm{~h}$.

The amount of metal supported on the different catalysts was determined by ICP analysis in a Varian SpectrAA-10 Plus instrument. The average mean diameter of metal nanoparticles of the different catalysts was measured by HRTEM images, which were acquired by using a JEM 1010 transmission electron microscope operated at $100 \mathrm{kV}$. The samples were prepared directly by dispersing the powders onto carbon copper grids.

Platinum dispersions were determined by $\mathrm{H}_{2}$ chemisorption at $35{ }^{\circ} \mathrm{C}$ in an ASAP $2010 \mathrm{C}$ Micromeritics instrument by extrapolating the total gas uptake in the adsorption isotherms at zero pressure. Prior to the measurements, the samples $(\sim 300$ $\mathrm{mg}$ ) were reduced under flowing pure $\mathrm{H}_{2}$ at $450{ }^{\circ} \mathrm{C}$ for $3 \mathrm{~h}$. The active metal surface area of each sample was estimated from the total amount of chemisorbed $\mathrm{H}_{2}$, assuming an adsorption $\mathrm{Pt} / \mathrm{H}$ stoichiometry of 2 , the $\mathrm{Pt}$ content (from ICP$\mathrm{OES}$ ), and considering spherical particle geometry with a surface atomic density of $8 \mathrm{~nm}^{2} /$ atom.

Powder X-ray diffraction patterns were collected in a Philips X'PERT diffractometer equipped with a proportional detector and a secondary graphite monochromator. Data were collected stepwise over the $2^{\circ} \leq 2 \theta \leq 40^{\circ}$ angular region, with steps of $0.02^{\circ} 2 \theta$, an accumulation time of $20 \mathrm{~s} / \mathrm{step}$, and $\mathrm{Cu} \operatorname{KR}(\lambda=$ $1.54178 \AA$ ) radiation.

In situ Fourier transform infrared (FTIR) experiments were performed with a Nexus 8700 FTIR spectrometer using a DTGS detector at $4 \mathrm{~cm}^{-1}$ resolution. For the in situ catalytic IR experiments, a quartz IR cell allowing in situ treatments in a controlled atmosphere and temperatures from 25 to $600{ }^{\circ} \mathrm{C}$ was connected to a vacuum system with gas dosing facility. Prior to the adsorption experiments, the samples were treated at $120{ }^{\circ} \mathrm{C}$ in a $\mathrm{H}_{2}$ flow $\left(20 \mathrm{~mL} \mathrm{~min}^{-1}\right)$ for $1.5 \mathrm{~h}$ followed by evacuation at $10^{-5}$ mbar at the same temperature for $1 \mathrm{~h}$. Then the samples were cooled to $25{ }^{\circ} \mathrm{C}$ under dynamic vacuum conditions followed by co-adsorption of 2-nitrobenzaldehyde ( 8 mbar) and $\mathrm{H}_{2}$ (40 mbar). IR spectra were recorded over time. For the IR studies of CO adsorption, a homemade stainless steel IR cell allowing in situ treatments in a controlled atmosphere and temperatures from -170 to $500{ }^{\circ} \mathrm{C}$ was used. Samples were activated as described above and then cooled to $-170{ }^{\circ} \mathrm{C}$ under dynamic vacuum conditions. $\mathrm{CO}$ dosing was performed at $-170{ }^{\circ} \mathrm{C}$ and at increasing pressures $(0.05-0.5$ mbar). IR spectra were recorded after each dosage. Origin software was used to treat the spectra. 
General Procedure for Reduction of 2-Nitroacylarenes. The catalyst and a solution of 2-nitroacylarene ( $1 \mathrm{mmol})$, with dodecane as the internal standard ( $40 \mathrm{mg}, 0.23 \mathrm{mmol})$, in $2 \mathrm{~mL}$ of toluene were placed in a $5 \mathrm{~mL}$ autoclave. The autoclave was pressurized at 9 bar of hydrogen and heated at $30{ }^{\circ} \mathrm{C}$ while its contents were being vigorously stirred.

In all reactions, samples were taken at regular intervals, diluted with dichloromethane, and analyzed by a gas chromatograph equipped with an HP5 capillary column $(30 \mathrm{~m} \times 0.25$ $\mathrm{mm}$ ) and $0.25 \mathrm{~mm}$ cross-linked $5 \%$ phenylmethylsiloxane and a FID as the detector. In all cases, the molar balance was $\geq 95 \%$. Mass spectra were recorded by a GC-MS HP Agilent 5973 instrument with a 6980 mass selective detector.

The products were purified by recrystallization from ethanol and identified by GC-MS and ${ }^{13} \mathrm{C}$ and ${ }^{1} \mathrm{H}$ nuclear magnetic resonance (NMR). ${ }^{1} \mathrm{H}$ NMR spectra were recorded at 300 $\mathrm{MHz}$ and ${ }^{13} \mathrm{C}$ NMR spectra at $75 \mathrm{MHz}$ in a Bruker Avance 300 spectrometer, and the chemical shifts in parts per million were reported with respect to internal TMS.

For catalyst recycling studies, the solid was collected by filtration, washed thoroughly with $\mathrm{CH}_{2} \mathrm{Cl}_{2}$, and calcined at 550 ${ }^{\circ} \mathrm{C}$ in a nitrogen flow for $3 \mathrm{~h}$ and then with a hydrogen flow for an additional $3 \mathrm{~h}$.

A large scale experiment was performed using $5 \mathrm{mmol}$ of 2 nitroacetophenone, $10 \mathrm{~mL}$ of toluene, and $0.1 \mathrm{wt} \% \mathrm{Pt} / \mathrm{MgO}$ (200 mg) at 9 bar of $\mathrm{H}_{2}$ and $30{ }^{\circ} \mathrm{C}$.

For the $\mathrm{Hg}(0)$ poisoning experiment, 0.1 wt \% $\mathrm{Pt} / \mathrm{MgO}(40$ $\mathrm{mg})$, 2-nitroacetophenone (1 mmol), $\mathrm{Hg}(0)(200 \mathrm{mg})$, and dodecane as an internal standard ( $40 \mathrm{mg}, 0.23 \mathrm{mmol}$ ) in $2 \mathrm{~mL}$ of toluene were placed in an autoclave, which was pressurized at 9 bar of hydrogen and heated at $30{ }^{\circ} \mathrm{C}$ while its contents were being vigorously stirred for $2 \mathrm{~h}$.

NMR Data. 3-Methyl-2,1-benzisoxazole (2a). ${ }^{1} \mathrm{H}$ NMR $\left(\mathrm{CDCl}_{3}, 300 \mathrm{MHz}\right): \delta 7.45(\mathrm{~d}, J=8.82 \mathrm{~Hz}, 1 \mathrm{H}), 7.32(\mathrm{~d}, J=$ $9.09 \mathrm{~Hz}, 1 \mathrm{H}), 7.16(\mathrm{dd}, J=9.09,6.3 \mathrm{~Hz}, 1 \mathrm{H}), 6.92(\mathrm{dd}, J=$ 8.82, $6.3 \mathrm{~Hz}, 1 \mathrm{H}), 3.14(\mathrm{~s}, 3 \mathrm{H}) .{ }^{13} \mathrm{C} \mathrm{NMR}\left(\mathrm{CDCl}_{3}, 75 \mathrm{MHz}\right): \delta$ $165.6(\mathrm{C}), 157.1(\mathrm{C}), 130.8(\mathrm{CH}), 122.8(\mathrm{CH}), 119.8(\mathrm{CH})$, $115.6(\mathrm{CH}), 114.9(\mathrm{C}), 11.9\left(\mathrm{CH}_{3}\right) . \mathrm{MS} \mathrm{m} / \mathrm{z}(\%) \mathrm{M}^{+\bullet}: 133$ (100), 104 (60), 90 (10), 78 (27), 62 (16), 51 (10), 43 (49), 15 (1).

2,1-Benzisoxazole (2b). ${ }^{1} \mathrm{H}$ NMR $\left(\mathrm{CDCl}_{3}, 300 \mathrm{MHz}\right): \delta$ $9.12(\mathrm{~s}, 1 \mathrm{H}), 7.60(\mathrm{~d}, J=9.09 \mathrm{~Hz}, 1 \mathrm{H}), 7.53(\mathrm{~d}, J=8.82 \mathrm{~Hz}$, $1 \mathrm{H}), 7.29$ (dd, $J=9.09,6.4 \mathrm{~Hz}, 1 \mathrm{H}), 6.98(\mathrm{dd}, J=8.82,6.4 \mathrm{~Hz}$, 1H). ${ }^{13} \mathrm{C} \mathrm{NMR}\left(\mathrm{CDCl}_{3}, 75 \mathrm{MHz}\right): \delta 156.1(\mathrm{CH}), 154.5(\mathrm{C})$, $130.8(\mathrm{CH}), 124.4(\mathrm{CH}), 119.6(\mathrm{CH}), 118.2(\mathrm{C}), 115.0(\mathrm{CH})$. MS $m / z(\%) \mathrm{M}^{+\bullet}: 119$ (87), 92 (100), 64 (60), 38 (18), 28 (49).

3-Methyl[1,3]dioxolo[ $\left[4^{\prime}, 5^{\prime}: 4,5\right]$ benzisoxazole (2c). ${ }^{1} \mathrm{H}$ $\mathrm{NMR}\left(\mathrm{CDCl}_{3}, 300 \mathrm{MHz}\right): \delta 6.62(\mathrm{~s}, 1 \mathrm{H}), 6.45(\mathrm{~s}, 1 \mathrm{H}), 5.88$ (s, 2H), $3.22(\mathrm{~s}, 3 \mathrm{H}) .{ }^{13} \mathrm{C}$ NMR $\left(\mathrm{CDCl}_{3}, 75 \mathrm{MHz}\right): \delta 162.7$ (C), $156.3(\mathrm{C}), 152.9(\mathrm{C}), 146.5(\mathrm{C}), 101.6\left(\mathrm{CH}_{2}\right), 92.4(\mathrm{CH})$, $89.5(\mathrm{CH}), 112.2(\mathrm{C}), 12\left(\mathrm{CH}_{3}\right)$. MS $m / z(\%) \mathrm{M}^{+\bullet}: 177(69)$, 148 (100), 121 (7), 105 (7), 91 (10), 77 (12), 68 (12), 53 (22), 43 (43), 28 (27).

5-Methoxy-2,1-benzisoxazole (2d). ${ }^{1} \mathrm{H}$ NMR $\left(\mathrm{CDCl}_{3}, 300\right.$ $\mathrm{MHz}): \delta 8.91(\mathrm{~s}, 1 \mathrm{H}), 7.51(\mathrm{~d}, J=9.57 \mathrm{~Hz}, 1 \mathrm{H}), 7.0(\mathrm{dd}, J=$ 9.57, $2.2 \mathrm{~Hz}, 1 \mathrm{H}), 6.59(\mathrm{~s}, 1 \mathrm{H}), 3.79(\mathrm{~s}, 3 \mathrm{H}) .{ }^{13} \mathrm{C}$ NMR $\left(\mathrm{CDCl}_{3}, 75 \mathrm{MHz}\right): \delta 156.1(\mathrm{C}), 154.3(\mathrm{C}), 152.3(\mathrm{CH}), 128.2$ $(\mathrm{CH}), 118.3(\mathrm{C}), 116.4(\mathrm{CH}), 92.8(\mathrm{CH}), 55.3\left(\mathrm{CH}_{3}\right) . \mathrm{MS} \mathrm{m} /$ $z(\%) \mathrm{M}^{+\bullet}: 149$ (54), 133 (7), 122 (19), 106 (100), 79 (19), 52 (19), 29 (7).

5-Bromo-3-methyl-2,1-benzisoxazole (2e). ${ }^{1} \mathrm{H}$ NMR $\left(\mathrm{CDCl}_{3}, 300 \mathrm{MHz}\right): \delta 7.52(\mathrm{~s}, 1 \mathrm{H}), 7.31(\mathrm{~d}, J=9.42 \mathrm{~Hz}$,
$1 \mathrm{H}), 7.18(\mathrm{dd}, J=9.42,1.59 \mathrm{~Hz}, 1 \mathrm{H}), 2.66(\mathrm{~s}, 3 \mathrm{H}) .{ }^{13} \mathrm{C}$ NMR $\left(\mathrm{CDCl}_{3}, 75 \mathrm{MHz}\right)$ : $165.4(\mathrm{C}), 155.4(\mathrm{C}), 134.6(\mathrm{CH}), 121.8$ $(\mathrm{CH}), 116.7(\mathrm{CH}), 116.6(\mathrm{CH}), 116.1(\mathrm{C}), 12.0\left(\mathrm{CH}_{3}\right) . \mathrm{MS}$ $m / z(\%) \mathrm{M}^{+\bullet}: 212$ (79), 211 (84), 183 (91), 182 (98), 158 (19), 156 (28), 132 (5), 117 (10), 104 (19), 90 (25), 77 (31), 61 (25), 50 (13), 43 (100), 38 (13), 15 (3).

\section{RESULTS AND DISCUSSION}

It has been reported in the literature that for the reduction of nitroaromatics into phenylhydroxylamine derivatives using a catalyst based on Pd and, especially, Pt are preferred over supported metals such as $\mathrm{Rh}, \mathrm{Ir}, \mathrm{Ru}$, and Os because of the higher activity and selectivity of the former. ${ }^{17}$ In fact, we recently showed that $0.2 \mathrm{wt} \% \mathrm{Pt} / \mathrm{C}$ with controlled crystal sizes is an efficient catalyst for the coupling of nitroarenes with aldehydes in the presence of $\mathrm{H}_{2}$ to obtain nitrones, ${ }^{18}$ and the mechanism involves the condensation of the hydroxylamine intermediate generated in situ with the benzaldehyde in a cascade type reaction. It was demonstrated that the formation of the hydroxylamine intermediate is favored by the presence of highly unsaturated $\mathrm{Pt}$ species. Furthermore, it has been reported recently in an interesting work that nitroaromatics can be chemoselectively reduced into phenylhydroxylamines in high yields using nanoparticles of Pt supported on carbon. ${ }^{19}$

From these precedents and considering that the reductive heterocyclization of 2-nitroacylarenes to 2,1-benzisoxazole involves the cyclization of the hydroxylamine intermediate by attack of the hydroxylamine group on the carbonyl group at position 2 (see Scheme 1), we envisaged that a properly designed $\mathrm{Pt} / \mathrm{C}$ catalyst could be a selective catalyst for preparing 2,1-benzisoxazole derivatives by reductive heterocyclization of 2-nitroacylarenes through a cascade type process.

Thus, taking 2-nitroacetophenone as a reactant model, we first tested $0.2 \mathrm{wt} \% \mathrm{Pt} / \mathrm{C}$ (average crystal size of $1.6 \mathrm{~nm}$ ) that was active for preparing nitrones. ${ }^{18}$ The reduction was performed at $30{ }^{\circ} \mathrm{C}$ under 9 bar of $\mathrm{H}_{2}$ in toluene as a solvent, and the kinetic plot of the reaction is presented in Figure 1. As one can see, the 2 -aminoacetophenone appears as a primary

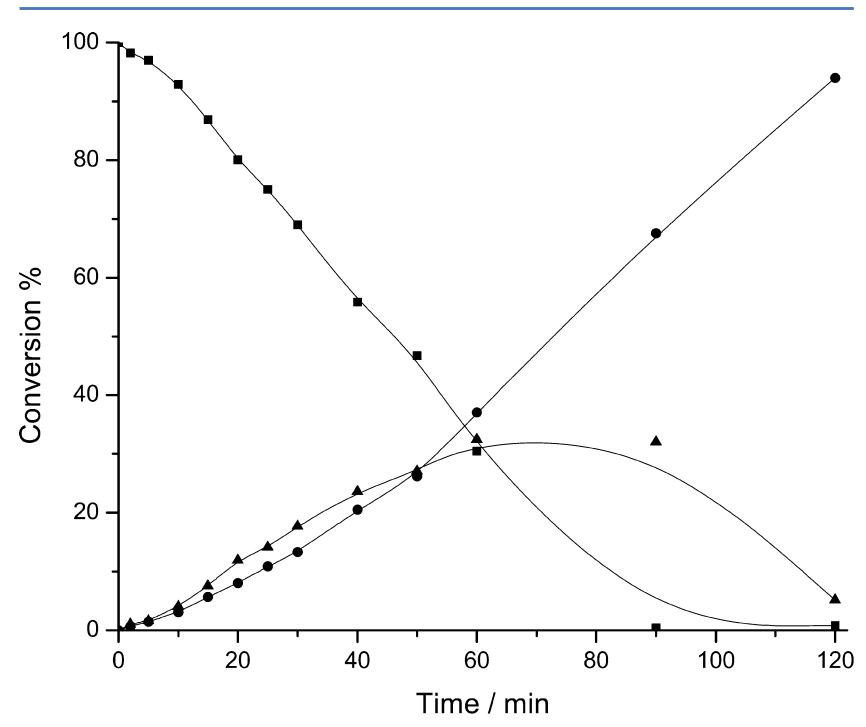

Figure 1. Hydrogenation of 2-nitroacetophenone using $0.2 \mathrm{wt} \% \mathrm{Pt} / \mathrm{C}$ as a catalyst: (ם) 2-nitroacetophenone, () 3-methyl-2,1-benzisoxazole, and (-) 2-aminoacetophenone. Reaction conditions: $0.2 \mathrm{wt} \%$ $\mathrm{Pt} / \mathrm{C}(40 \mathrm{mg})$, 2-nitroacetophenone $(1 \mathrm{mmol})$, toluene $(2 \mathrm{~mL}), 9 \mathrm{bar}$ of $\mathrm{H}_{2}$ at $30{ }^{\circ} \mathrm{C}$. 
and secondary product that can be formed by fast hydrogenation of the 2-nitroacetophenone into amino (primary character), as well as by further reduction of the desired 2,1benzisoxazole (see Scheme 2), which appears as a primary and unstable product.

From these results, we can conclude that although the $0.2 \mathrm{wt}$ $\% \mathrm{Pt} / \mathrm{C}$ catalyst promotes the formation of 2,1-benzisoxazole through the formation of the hydroxylamine intermediate, under our reaction conditions, this intermediate undergoes a fast reduction into 2-aminoacetophenone. Moreover, the catalyst also promotes the reductive cleavage of 2,1benzisoxazole in high extension.

Similar results were obtained when the hydrogenation was performed with $\mathrm{Pt}$ supported on $\mathrm{TiO}_{2}\left(0.2\right.$ wt \% $\mathrm{Pt} / \mathrm{TiO}_{2}$ ) activated at $450{ }^{\circ} \mathrm{C}$ in the presence of hydrogen (see Figure 2),

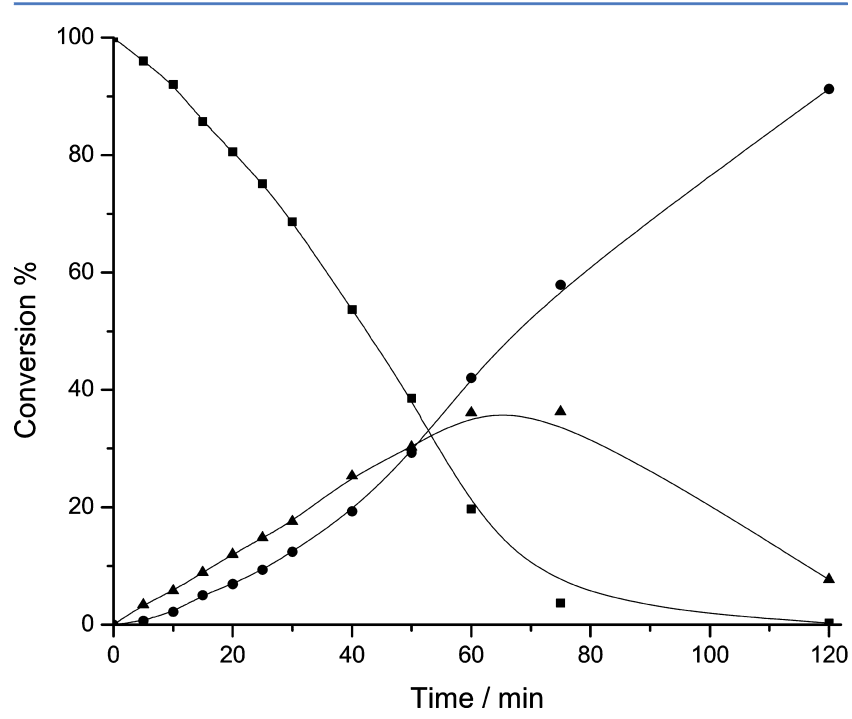

Figure 2. Hydrogenation of 2-nitroacetophenone using a $0.2 \mathrm{wt} \% \mathrm{Pt} /$ $\mathrm{TiO}_{2}$ catalyst: $(\mathbf{\square})$ 2-nitroacetophenone, (๑) 2-aminoacetophenone, and $(\boldsymbol{\Delta})$ 3-methyl-2,1-benzisoxazole. Reaction conditions: $0.2 \mathrm{wt} \%$ $\mathrm{Pt} / \mathrm{TiO}_{2}(40 \mathrm{mg})$, 2-nitroacetophenone (1 mmol), toluene (2 mL), 9 bar of $\mathrm{H}_{2}$ at $30^{\circ} \mathrm{C}$.

although in this case the results are not surprising because of the role attributed to $\mathrm{TiO}_{2}$ in minimizing the formation of the hydroxylamine intermediate during the hydrogenation of nitro compounds. $^{20}$

It has been demonstrated in our previous study ${ }^{21}$ that the basicity of surface oxygen species favors the stabilization of nitroso and hydroxylamine intermediate compounds. Then, in an attempt to stabilize the intermediate hydroxylamine to enhance the cyclization reaction, we have selected $\mathrm{MgO}$ as a basic support for $\mathrm{Pt}$.

Then, a catalyst that contains $0.2 \mathrm{wt} \% \mathrm{Pt}$ on $\mathrm{MgO}$ (0.2 wt \% $\mathrm{Pt} / \mathrm{MgO})$ was prepared. The average Pt crystallite size in this catalyst was $2.4 \mathrm{~nm}$ (see Table S1). The catalytic results depicted in Figure 3 show that the concentration of 2,1benzisoxazole reaches a maximum yield of approximately $80 \%$ at $100 \%$ reactant conversion when working with the $\mathrm{Pt} / \mathrm{MgO}$ catalyst. Longer reaction times led to further hydrogenation of 2,1-benzisoxazole into 2-aminoacetophenone, which correspondingly showed a marked character as a secondary product. Moreover, a minor amount of a compound that was tentatively assigned to a dimer of the nitrosobenzene intermediate (azodioxide) was also detected during the reaction.

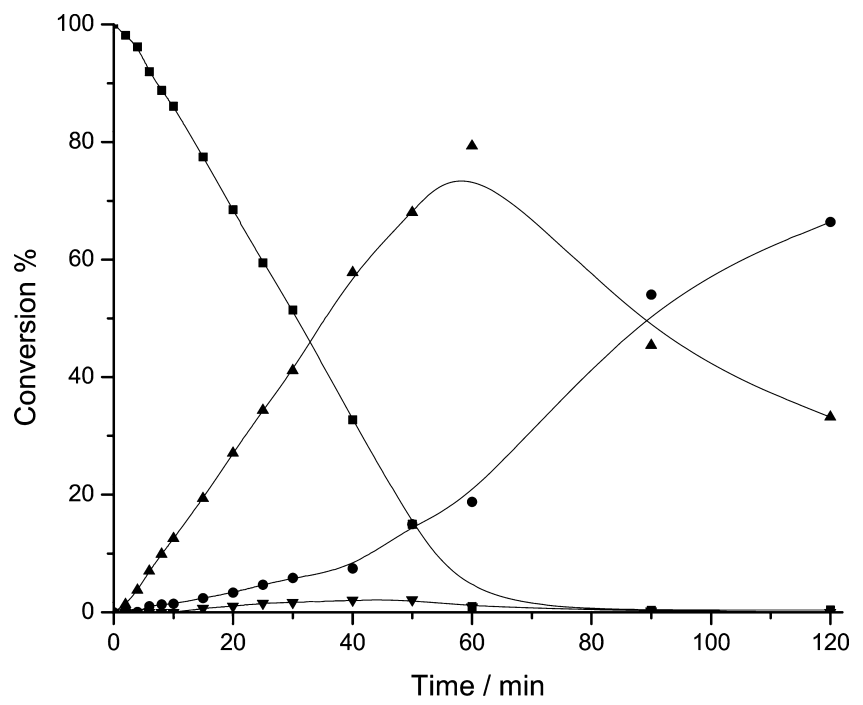

Figure 3. Hydrogenation of 2-nitroacetophenone using $0.2 \mathrm{wt} \% \mathrm{Pt} /$

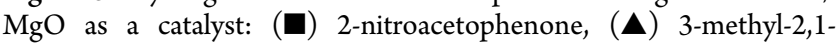
benzisoxazole, $(\boldsymbol{\bullet})$ 2-aminoacetophenone, and $(\boldsymbol{\nabla})$ azodioxide $\left(M_{\mathrm{r}}=\right.$ $266 \mathrm{~g} / \mathrm{mol}$ ). Reaction conditions: $0.2 \mathrm{wt} \% \mathrm{Pt} / \mathrm{MgO}$ (40 mg), 2 nitroacetophenone $(1 \mathrm{mmol})$, toluene $(2 \mathrm{~mL}), 9$ bar of $\mathrm{H}_{2}$ at $30^{\circ} \mathrm{C}$.

Notice that in the case of 0.2 wt $\% \mathrm{Pt} / \mathrm{MgO}$, which gives catalytic results that are better than those with $0.2 \mathrm{wt} \% \mathrm{Pt} / \mathrm{C}$, the support has been changed and the average crystallite size of the Pt was different.

Therefore, we cannot conclude if the improvement is due to an intrinsic effect of the support on the catalytic process or an indirect effect of the support on metal dispersion. To gain a better physicochemical understanding of our catalytic system, while improving its catalytic behavior, we prepared different $\mathrm{Pt}$ on $\mathrm{MgO}$ catalysts in which the Pt dispersion was changed. By doing this, we could have $\mathrm{Pt} / \mathrm{MgO}$ samples with different average metal Pt crystallite sizes. Thus, by changing the metal crystallite size, one not only can change the ratio of exposed to nonexposed metal atoms, which may reflect total conversion, but also can change the relative ratio of accessible $\mathrm{Pt}$ atoms located at the crystal corners (less saturated metal atoms) versus the accessible $\mathrm{Pt}$ atoms located on crystal faces, this ratio being higher when the crystal size is smaller. Because the electronic properties of those more unsaturated $\mathrm{Pt}$ atoms should be different, the activity (as per turnover frequency) and selectivity of the final catalyst could be modified by changing the crystal size of the metal nanoparticle.

Then three additional $\mathrm{Pt} / \mathrm{MgO}$ samples with $0.1,0.5$, and 1 wt $\% \mathrm{Pt}$ were prepared (see the Experimental Section), and the average crystallite sizes obtained from the corresponding histograms are listed in Table S1.

Kinetic curves for the conversion of 2-nitroacetophenone with these new samples are given in Figures S1-S4. In Table 1 are summarized the results of the turnover frequency (TOF), conversion, and selectivity to 3-methyl-1,2-benzisoxazole obtained with the different catalysts. It can be seen from those results that the TOF (calculated as the initial rate of formation of benzisoxazole divided by the moles of surface $\mathrm{Pt}$ atoms) increases when the Pt metal crystallite size decreases. This would indicate that the less saturated Pt metal atoms located at the corners play a key role in this multistep reaction. Very importantly, the maximum yield of the 3-methyl-2,1benzisoxazole (2) (94\%) obtained at $100 \%$ conversion of 2 - 
Table 1. Results of the Reductive Heterocyclization of 2-Nitroacetophenone Using Pt/MgO Samples with Different Crystal Sizes $^{a}$

$\begin{array}{ccccccc}\text { entry } & \text { Pt loading }(\mathrm{wt} \%) & \text { crystal size }(\mathrm{nm}) & r^{\circ b}\left(\times 10^{5} \mathrm{~mol} / \mathrm{h}\right) & \mathrm{TOF}^{c}\left(\mathrm{~h}^{-1}\right) & \text { conversion of } \mathbf{1}(\%) & \text { selectivity of } \mathbf{2}(\%) \\ 1 & 1.0 & 8.7 & 56.2 & 73.7 & 2960 & 100 \\ 2 & 0.5 & 3.0 & 75.8 & 5820 & 100 \\ 3 & 0.2 & 2.4 & 120.6 & 7220 & 72\end{array}$

${ }^{a}$ Reaction conditions: 4877 substrate/Pt molar ratio, 2-nitroacetophenone $(1 \mathrm{mmol}), 30{ }^{\circ} \mathrm{C}$, toluene $(2 \mathrm{~mL}), 9 \mathrm{bar}$ of $\mathrm{H}_{2}, 60 \mathrm{~min}$ reaction time. ${ }^{b}$ Initial rate of appearance of 3-methyl-2,1-benzisoxazole. ${ }^{c}$ Initial reaction rate of formation of 3-methyl-2,1-benzisoxazole divided by the moles of surface $\mathrm{Pt}$ atoms (determined by chemisorption of $\mathrm{H}_{2}$ ).

nitroacetophenone is obtained with the $\mathrm{Pt} / \mathrm{MgO}$ catalyst (TON of 4700) with the smallest crystallite size $(1.1 \mathrm{~nm})$. From these results, we can then conclude that when the crystal size of the metal Pt decreases and the relative amount of less saturated $\mathrm{Pt}$ atoms on the surface increases the catalyst becomes more active for the reductive heterocyclization and less active for the reductive cleavage, which shows a marked sensitivity to the architecture of the Pt nanoparticles.

Nevertheless, we want to point out that while the average crystallite size of the most active and selective $\mathrm{Pt} / \mathrm{MgO}$ (1.1 $\mathrm{nm})$ is not that different from that of $\mathrm{Pt} / \mathrm{C}(1.6 \mathrm{~nm})$, the TOF and selectivity for 2,1-benzisoxazole are much lower for the latter $\left(990 \mathrm{~h}^{-1}\right.$ and 5\% selectivity at $100 \%$ conversion for $\mathrm{Pt} / \mathrm{C}$ vs $7220 \mathrm{~h}^{-1}$ and $94 \%$ selectivity at the same conversion for $\mathrm{Pt} /$ $\mathrm{MgO})$. This observation indicates either a direct effect of the support or an indirect effect where the support may influence the shape of the $\mathrm{Pt}$ crystals. To distinguish between both effects, a detailed spectroscopic study based on IR spectroscopy was performed on the 0.2 wt \% $\mathrm{Pt} / \mathrm{C}$ and 0.2 wt $\% \mathrm{Pt} / \mathrm{MgO}$ samples. Differences in particle shape are hard to visualize by means of our HRTEM study; therefore, we have used IR spectroscopy of $\mathrm{CO}$ adsorption as a more convenient way to titrate the nature of surface sites. The IR spectra of CO adsorption (Figure 4) show less saturated Pt surface sites on the $0.2 \mathrm{wt} \% \mathrm{Pt} / \mathrm{C}$ sample (IR band at $2040 \mathrm{~cm}^{-1}$ ) than on the 0.2 wt $\% \mathrm{Pt} / \mathrm{MgO}$ sample (IR band at $2060 \mathrm{~cm}^{-1}$ ), the latter being more selective for 2,1-benzisoxazole. Thus, we can say that the selectivity for 2,1-benzisoxazole is related to the presence of unsaturated surface sites and to factors other than particle size and shape.

To unravel this behavior, the reaction mechanism has been followed in situ by IR spectroscopy taking 2-nitrobenzaldehyde as the reactant model. Thus, 2-nitrobenzaldehyde and $\mathrm{H}_{2}$ were co-adsorbed in the presence of the catalyst, and the evolution of reaction intermediate surface species was monitored over time by IR spectroscopy. On the $0.2 \mathrm{wt} \% \mathrm{Pt} / \mathrm{C}$ sample (Figure 5), 2 -aminobenzaldehyde was detected on the catalyst surface in the first minutes of the reaction (IR bands at 1601, 1570, and $1558 \mathrm{~cm}^{-1}$ ) while no other intermediate products were visualized, indicating a fast rate of hydrogenation of the nitro group to the amino group.

On the other hand, on the $0.2 \mathrm{wt} \% \mathrm{Pt} / \mathrm{MgO}$ sample (Figure 6), nitrosobenzaldehyde (IR band at $1485 \mathrm{~cm}^{-1}$ ) and hydroxylamine $\left(1490 \mathrm{~cm}^{-1}\right)$ were detected in the first minutes of the reaction (see the inset of Figure 6), while at increasing reaction times, new IR bands at 1638, 1539, 1515, and 1482 $\mathrm{cm}^{-1}$ could be envisaged, corresponding to 2,1-benzisoxazole. 2-Aminobenzaldehyde was hard to detect, specifically considering the bad quality of the IR spectra due to the large amount of carbonate species on the support.
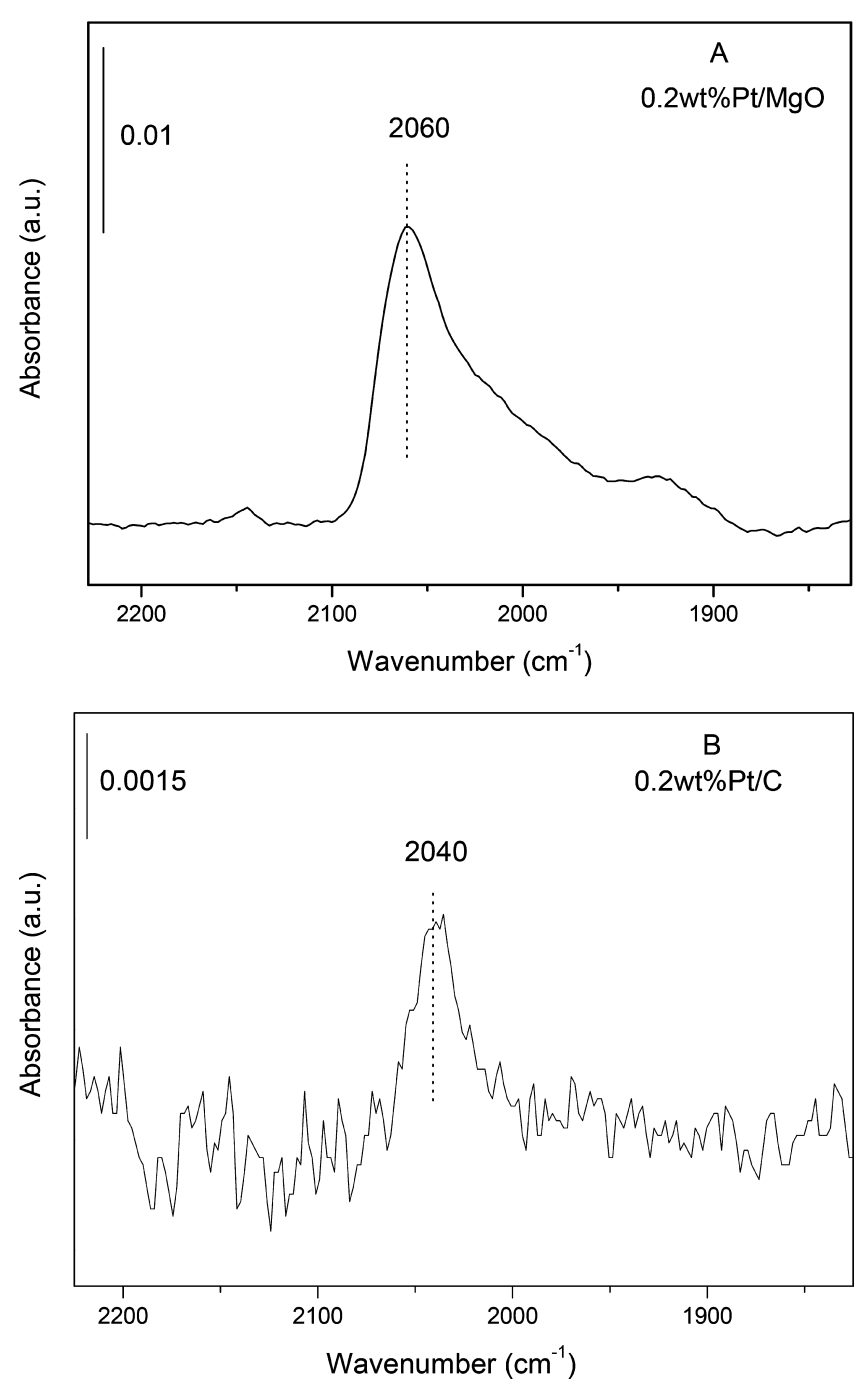

Figure 4. IR spectra of $\mathrm{CO}$ adsorption on (A) $0.2 \mathrm{wt} \% \mathrm{Pt} / \mathrm{MgO}$ and (B) 0.2 wt $\% \mathrm{Pt} / \mathrm{C}$ acquired at $-170{ }^{\circ} \mathrm{C}$ and $0.5 \mathrm{mbar}$ of $\mathrm{CO}$.

According to previous studies performed by our group, ${ }^{21}$ the higher basicity of the $\mathrm{MgO}$ support may explain the stabilization of the hydroxylamine intermediate compound, where accumulation of hydroxylamine on the catalyst surface would favor their cyclization versus hydrogenation. In a similar way, the basicity of the support enhances stabilization of 2,1benzisoxazole. This has been proven by a control experiment in which 2,1-benzisoxazole has been adsorbed on a fresh $0.2 \mathrm{wt} \%$ $\mathrm{Pt} / \mathrm{MgO}$ sample where it remains stable even after vacuum treatment (see Figure S5 for details) and in the presence of $\mathrm{H}_{2}$ as observed in Figure 6. 


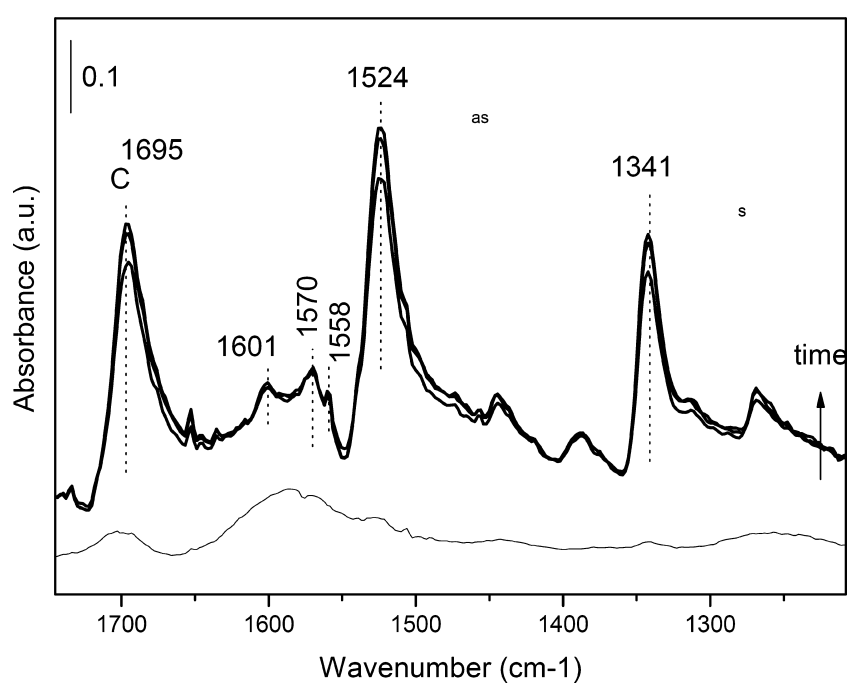

Figure 5. Time evolution of IR surface species on the $0.2 \mathrm{wt} \% \mathrm{Pt} / \mathrm{C}$ catalyst during the hydrogenation of 2-nitrobenzaldehyde $(8 \mathrm{mbar}$ of 2-nitrobenzaldehyde and $40 \mathrm{mbar}$ of $\mathrm{H}_{2}$ at $25^{\circ} \mathrm{C}$ ). The thin line is for the sample before reaction and the thick line for the sample during the reaction. Spectra were acquired at 7,52 , and $150 \mathrm{~min}$. IR bands at 1695,1524 , and $1341 \mathrm{~cm}^{-1}$ are due to 2-nitrobenzaldehyde.

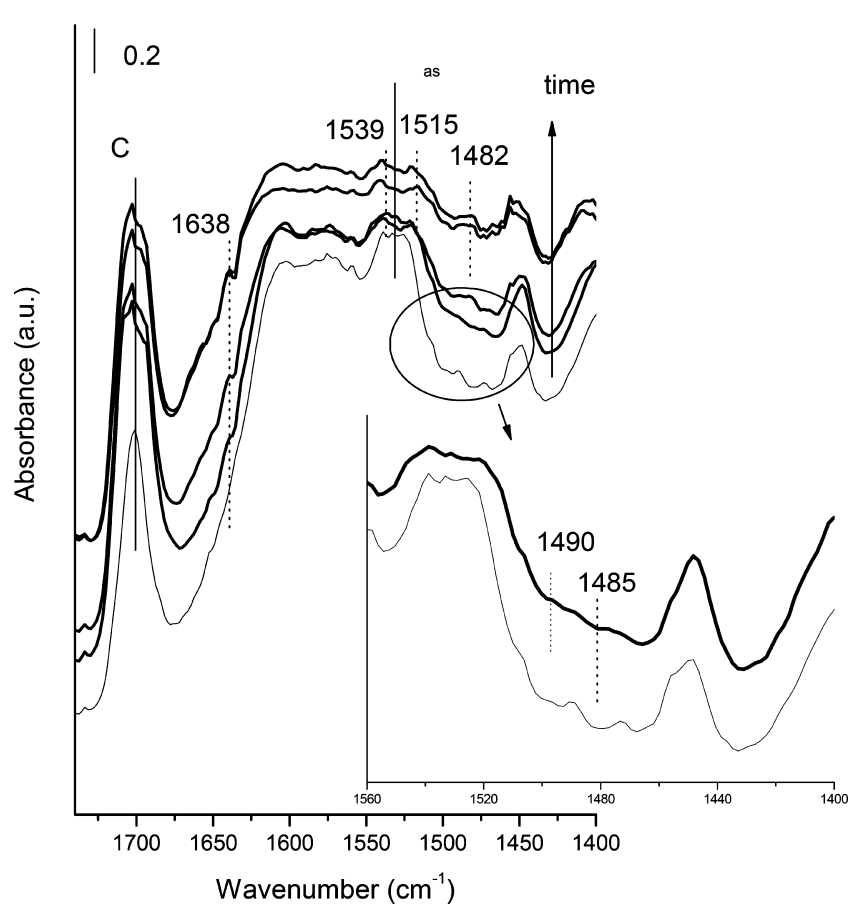

Figure 6. Time evolution of IR surface species on the $0.2 \mathrm{wt} \% \mathrm{Pt} /$ $\mathrm{MgO}$ catalyst during the hydrogenation of 2-nitrobenzaldehyde (8mbar of 2-nitrobenzaldehyde and $40 \mathrm{mbar}$ of $\mathrm{H}_{2}$ at $25{ }^{\circ} \mathrm{C}$ ). The thin line is for the sample before reaction and the thick line for the sample during the reaction. Spectra were acquired at 7, 52, 110, and $200 \mathrm{~min}$.

From these results, we can then conclude that the higher basicity of the $\mathrm{MgO}$ support plays a key role enhancing the selectivity for 2,1-benzisoxazole. Moreover, the higher rate of 2aminoacylarene formation observed on the $0.2 \mathrm{wt} \% \mathrm{Pt} / \mathrm{C}$ sample, in the IR and catalytic studies, can be related to a more pronounced activation of the carbonyl functional group in the case of the $0.2 \mathrm{wt} \% \mathrm{Pt} / \mathrm{C}$ sample. Indeed, the carbonyl group of adsorbed 2-nitrobenzaldehyde is shifted to lower frequencies in the $0.2 \mathrm{wt} \% \mathrm{Pt} / \mathrm{C}$ sample $\left(1695 \mathrm{~cm}^{-1}\right)$ versus the $0.2 \mathrm{wt} \%$ PtMgO sample $\left(1702 \mathrm{~cm}^{-1}\right)$ (see Figure S6). In this case, we can assume that activation of the carbonyl group causes an electronic withdrawal effect that enhances the electrophilicity of the nitro group, increasing their rate of hydrogenation to the amino group. Similar effects have already been reported in the literature. $^{19}$

On the other hand, it is interesting to point out that for the preparation of $\mathrm{Pt} / \mathrm{MgO}$ samples we selected platinum(II) acetylacetonate as a source of $\mathrm{Pt}$ instead of $\mathrm{H}_{2} \mathrm{PtCl}_{6}$ considering the results previously reported by Aramendia et al. ${ }^{22}$ In their work, the authors found that the use of chlorine-containing metal precursors $\left(\mathrm{H}_{2} \mathrm{PtCl}_{6}\right)$ to prepare $\mathrm{Pt} / \mathrm{MgO}$ had an adverse effect on the chemical and textural properties of the resulting solid, decreasing the specific surface area and basicity of the support. Therefore, to determine the possible role of the metal precursor in the catalytic activity of $\mathrm{Pt} / \mathrm{MgO}$, we prepared a 0.1 wt $\% \mathrm{Pt} / \mathrm{MgO}$ sample using $\mathrm{H}_{2} \mathrm{PtCl}_{6}$ as the $\mathrm{Pt}$ source. The sample, with a metal size determined by TEM of $1.2 \mathrm{~nm}$, was tested in the reductive heterocyclization of 2-nitroacetophenone under the same reaction conditions (Figure S7). The results showed that the catalytic activity and selectivity for 3methyl-2,1-benzisoxazole are very different from those obtained with 0.1 wt $\% \mathrm{Pt} / \mathrm{MgO}$ [prepared with platinum(II) acetylacetonate (see Figure S1)]. Thus, with the catalyst prepared with $\mathrm{H}_{2} \mathrm{PtCl}_{6}$, the rate of appearance of 2,1benzisoxazole was lower, while the selectivity at $100 \%$ conversion was only $76 \%$.

Influence of the Temperature of the Reaction. To study the influence of the reaction temperature on selectivity, the process was performed at increased temperatures (50, 70, and $90{ }^{\circ} \mathrm{C}$ ) using a $0.1 \mathrm{wt} \% \mathrm{Pt} / \mathrm{MgO}$ sample. In Figure 7 is presented the yield of 3-methyl-2,1-benzisoxazole versus conversion. As one can see, an increase in temperature leads to a decrease in selectivity for 2,1-benzisoxazole, indicating that the reductive cleavage should have a higher activation energy.

Stability and Reusability of Pt/MgO. To investigate if the catalytic process involves $\mathrm{Pt}$ that leached into the solution, an

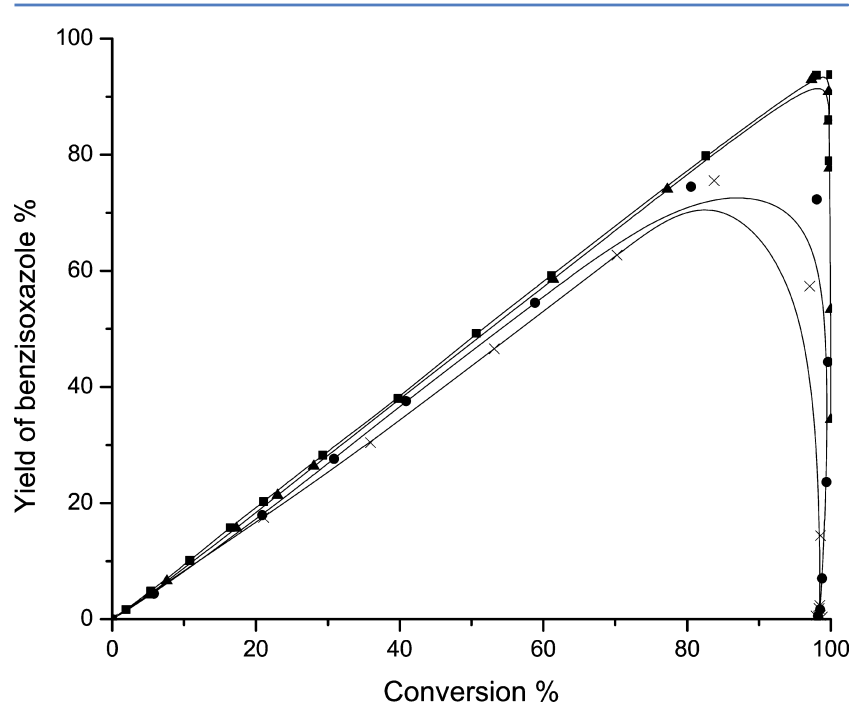

Figure 7. Influence of the reaction temperature on the selectivity for 3methyl-2,1-benzisoxazole using 0.1 wt $\% \mathrm{Pt} / \mathrm{MgO}$ as a catalyst. Reaction conditions: $0.1 \mathrm{wt} \% \mathrm{Pt} / \mathrm{MgO}$ (40 mg), 2-nitroacetophenone

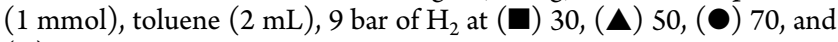
(x) $90{ }^{\circ} \mathrm{C}$. 
additional experiment was performed whereby the reduction of 2-nitroacetophenone with $0.2 \mathrm{wt} \% \mathrm{Pt} / \mathrm{MgO}$ was stopped after $30 \mathrm{~min}$. At this point, the catalyst was filtered off and the reaction was continued for an additional $1 \mathrm{~h}$, but no further conversion was detected (Figure S8).

Additionally, a $\mathrm{Hg}(0)$ poisoning test was performed to corroborate the heterogeneous nature of the active species. $\mathrm{Hg}(0)$ poisons metal(0) catalysts by forming an amalgam with the metal and/or adsorbing onto the metal surface. ${ }^{23}$ Then, the heterocyclization of 2-nitroacetophenone was performed using 0.1 wt \% Pt/MgO in the presence of $200 \mathrm{mg}$ of $\mathrm{Hg}$, and after 2 $\mathrm{h}$, the conversion was only $2 \%$. The strong inhibition of the reaction upon addition of $\mathrm{Hg}(0)$ is indicative of the heterogeneous nature of the active species.

To check the reusability of the catalyst, after a first run, the 0.1 wt \% Pt $/ \mathrm{MgO}$ sample was recovered by filtration, washed thoroughly with dichloromethane, and used in a second cycle. The results showed an important decrease in activity (an only $10 \%$ yield of 2,1-benzisoxazole was obtained), indicating strong catalyst deactivation, which could be caused by strong adsorption of organic material on the catalyst surface. Indeed, the TG analysis of the used catalyst showed that $32 \mathrm{wt} \%$ (with respect to the amount of catalyst) organic material remained on the catalyst. However, another possible cause of catalyst deactivation could be the existence of structural changes in the support. X-ray diffraction (XRD) analysis of the used catalyst showed the appearance of diffraction peaks corresponding to $\mathrm{Mg}(\mathrm{OH})_{2}$ (see Figure S9), which will be produced by hydration of $\mathrm{MgO}$ by the water produced during reaction. These observations suggest that deactivation of the catalyst could originate not only in the adsorption of organic material but also in changes in the basicity of the support as $\mathrm{Mg}(\mathrm{OH})_{2}$ is less basic than $\mathrm{MgO}^{24}$ However, the initial catalytic activity could be recovered by subjecting the catalyst to calcination at $550{ }^{\circ} \mathrm{C}$ under an air flow followed by reduction under a $\mathrm{H}_{2}$ flow at $450{ }^{\circ} \mathrm{C}$. Following this protocol, the catalyst could be reused three consecutive cycles without any loss of activity or selectivity (see Figure 8). Moreover, ICP analysis of the catalyst after the reaction showed that the amount of $\mathrm{Pt}$ on the catalyst remained constant during the three cycles.

The average mean diameter of metal nanoparticles was also measured by HRTEM after each cycle (see Table S2). The results showed that there is a slight increase in the size of the metal after each cycle, which has no effect on conversion or selectivity.

Because other metals such as $\mathrm{Au}$ and Pd have been reported as potential chemoselective catalysts for hydrogenation of nitro groups, 0.1 wt $\% \mathrm{Pd} / \mathrm{MgO}$ and 0.1 wt $\% \mathrm{Au} / \mathrm{MgO}$ were prepared following the same methodology and tested in the reduction of 2-nitroacetophenone. However, as one can see in Table 2, 0.1 wt \% Pd/MgO (1.9 nm Pd crystal size) was less active than $\mathrm{Pt} / \mathrm{MgO}$, although the selectivity for 2,1benzisoxazole was rather acceptable while $\mathrm{Au} / \mathrm{MgO}(2.3 \mathrm{~nm}$ $\mathrm{Au}$ crystal size) showed very low activity in this reaction.

Scope of the Reaction. The $0.1 \mathrm{wt} \% \mathrm{Pt} / \mathrm{MgO}$ catalyst was tested for the reductive heterocyclization of various 2nitroarylketone and 2-nitrobenzaldehyde derivatives (Table 3 ). Good conversions and selectivities for the corresponding 2,1-benzisoxazole derivatives were obtained with substrates bearing electron-donating groups in the aromatic ring (entries 3 and 4) or with withdrawing groups such as $\mathrm{Br}$ (entry 5), while in this case, dehalogenation as a side reaction was not observed. However, when the carbonyl group in the ortho position is

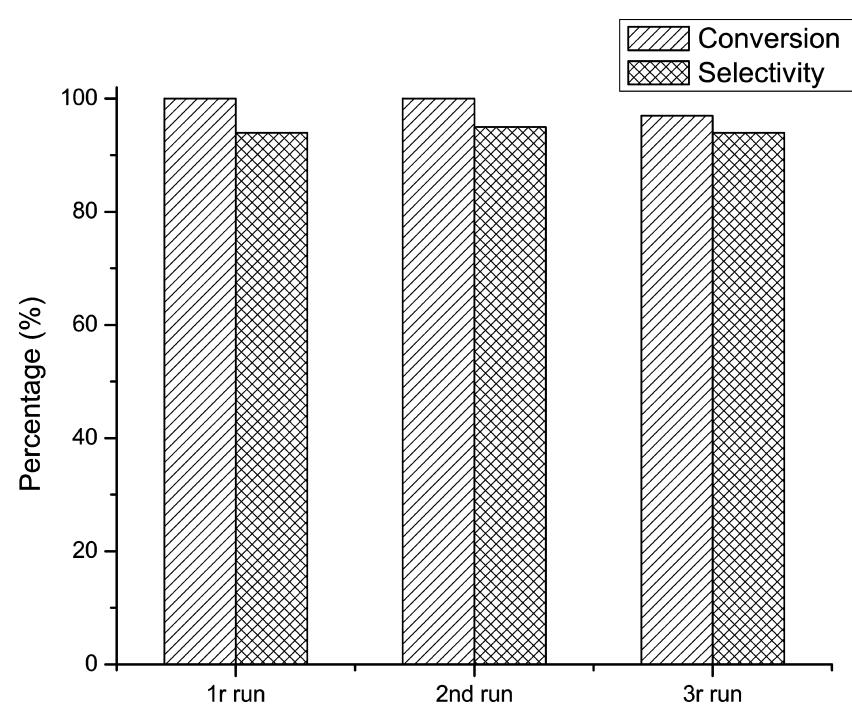

Figure 8. Reuse of the $0.1 \mathrm{wt} \% \mathrm{Pt} / \mathrm{MgO}$ sample in the reductive cyclization of 2-nitroacetophenone. Reaction conditions: $0.1 \mathrm{wt} \% \mathrm{Pt} /$ $\mathrm{MgO}$ (40 mg), 2-nitroacetophenone (1 mmol), toluene $(2 \mathrm{~mL}), 9$ bar of $\mathrm{H}_{2}$ at $30^{\circ} \mathrm{C}$ over $1 \mathrm{~h}$. After each use, the catalyst was calcined at 550 ${ }^{\circ} \mathrm{C}$ under an air flow for $3 \mathrm{~h}$ and reduced at $450{ }^{\circ} \mathrm{C}$ under a $\mathrm{H}_{2}$ flow.

integrated into an ester group, reductive heterocyclization was not observed, and the only observed compound was the corresponding 2-aminoester (entry 6). This result agrees with the previously reported results using $\mathrm{SnCl}_{2}$ for reducing 2nitroesters. $^{12}$

Finally, a large scale experiment was performed using $5 \mathrm{mmol}$ of 2-nitroacetophenone using a $0.1 \mathrm{wt} \% \mathrm{Pt} / \mathrm{MgO}$ catalyst (see Experimental Section). The results showed that after reaction for $4 \mathrm{~h}$ a conversion of $100 \%$ with $90 \%$ selectivity for 3-methyl2,1-benzisoxazole can be achieved.

\section{CONCLUSIONS}

2,1-Benzisoxazoles have been obtained by reductive heterocyclization of 2-nitroacylarenes using supported $\mathrm{Pt}$ nanoparticles. The reductive heterocyclization of 2-nitroacetophenone performed with $\mathrm{Pt}$ nanoparticles on different supports (C, $\mathrm{TiO}_{2}$, and $\mathrm{MgO}$ ) showed that $\mathrm{Pt} / \mathrm{MgO}$ was the most active and selective catalyst. Kinetic experiments combined with operando IR spectroscopy and HRTEM showed that while small $\mathrm{Pt}$ nanoparticles $(\sim 1 \mathrm{~nm})$ are necessary for a successful catalyst, this is not the only requirement for achieving high activity and selectivity. The reaction mechanism studied by in situ IR spectroscopy of the adsorbed reactant showed that the reduction of the nitro group on the Pt proceeds through the formation of the corresponding nitroso, hydroxylamine, and aniline derivatives. However, the relative rate of the different hydrogenation steps can be modified by the basicity of the support. Thus, it is possible to stabilize the hydroxylamine intermediate on the $\mathrm{Pt} / \mathrm{MgO}$ surface favoring their cyclization to the target compound versus hydrogenation. Moreover, the basicity of the support enhances the stabilization of the desired 2,1-benzisoxazole, preventing their further reductive cleavage. Then, the maximum activity and selectivity to the target compound can be achieved by controlling the architecture of metal particles and acid-base properties of the support. The optimized $\mathrm{Pt} / \mathrm{MgO}$ catalyst could be reused several times without loss of activity and could be applied to the synthesis of a variety of 2,1-benzisoxazole derivatives with high yields. 
Table 2. Results of the Reductive Heterocyclization of 2-Nitroacetophenone Using Different Metals Supported on MgO $^{a}$

$\begin{array}{cccccc}\text { catalyst } & \text { crystal size }(\mathrm{nm}) & r^{\circ}\left(\times 10^{5} \mathrm{~mol} / \mathrm{h}\right) & \text { time }(\mathrm{min}) & \text { conversion of } \mathbf{1}(\%) & \text { yield of } \mathbf{2}(\%) \\ 0.1 \text { wt } \% \mathrm{Pd} / \mathrm{MgO} & 1.9 & 35.90 & 90 & 100 & 63 \\ 0.1 \text { wt } \% \mathrm{Pt} / \mathrm{MgO} & 1.1 & 120.60 & 60 & 100 & 94 \\ 0.1 \text { wt } \% \mathrm{Au} / \mathrm{MgO} & 2.3 & 0.08 & 120 & 34\end{array}$

${ }^{a}$ Reaction conditions: 4877 substrate/metal molar ratio, 2-nitroacetophenone $(1 \mathrm{mmol})$, toluene $(2 \mathrm{~mL}), 9 \mathrm{bar}$ of $\mathrm{H}_{2}$ at $30{ }^{\circ} \mathrm{C}$.

Table 3. Reductive Heterocyclization of Different 2Nitroacylarenes Using 0.1 wt \% Pt/MgO as the Catalyst ${ }^{a}$

Entry

${ }^{a}$ Reaction conditions: $0.1 \mathrm{wt} \% \mathrm{Pt} / \mathrm{MgO}(40 \mathrm{mg})$, reactant $(1 \mathrm{mmol})$, toluene $(2 \mathrm{~mL}), 9$ bar of $\mathrm{H}_{2}$ at $30^{\circ} \mathrm{C}$.

\section{ASSOCIATED CONTENT}

\section{S Supporting Information}

The Supporting Information is available free of charge on the ACS Publications website at DOI: 10.1021/acscatal.7b01841.

TEM images and average particle sizes of the Ptsupported catalysts, kinetic data, XRD patterns of the used and regenerated catalyst, and IR spectra of adsorbed species (PDF)

\section{AUTHOR INFORMATION}

\section{Corresponding Authors}

*E-mail: acorma@itq.upv.es. Fax: (+34) 963877809. Phone: (+34) 963877800 .

*E-mail: mjcliol@qim.upv.es.

\section{ORCID}

A. Corma: 0000-0002-2232-3527

Notes

The authors declare no competing financial interest.

\section{ACKNOWLEDGMENTS}

Spanish MICINN Project (CTQ-2015-67592-P), Generalitat Valenciana (Prometeo Program), and Severo Ochoa Program are gratefully acknowledged.

\section{REFERENCES}

(1) Moriwaki, T.; Fürstner, C.; Riedl, B.; Ergüden, J. K.; Böss, F.; Schmidt, B.; van der Staay, F. J.; Schröder, W.; Schlemmer, K. H.; Yoshida, N. U.S. Patent 6589949, 2003.

(2) Chaker, A.; Najahi, E.; Chatriant, O.; Valentin, A.; Tene, N.; Treilhou, M.; Chabchoub, F.; Nepveu, F. Arabian J. Chem. 2017, 10, S2464-S2470.

(3) (a) Walsh, D. A.; Uwaydah, I. M. U.S. Patent 4898874, 1990.

(b) Walsh, D. A. EP 0260924, 1988. (c) Pierce, A. C.; Jacobs, M.; Stuver-Moody, C. J. Med. Chem. 2008, 51, 1972-1975.

(4) Haley, N. F. J. Org. Chem. 1978, 43, 1233-1237.

(5) (a) Lyssikatos, J. P.; Greca, S. D. L.; Yang, B. V. U.S. Patent 6495564, 2002. (b) Ogata, M.; Matsumoto, H.; Kano, H. Tetrahedron 1969, 25, 5205-5215.

(6) Kotov, A. D.; Prokaznikov, M. A.; Antonova, E. A.; Rusakov, A. I. Chem. Heterocycl. Compd. 2014, 50, 647-657.

(7) Więclaw, M.; Bobin, M.; Kwast, A.; Bujok, R.; Wróbel, Z.; Wojciechowski, K. Mol. Diversity 2015, 19, 807-816.

(8) Stokes, B. J.; Vogel, C. V.; Urnezis, L. K.; Pan, M.; Driver, T. G. Org. Lett. 2010, 12, 2884-2887.

(9) Otley, K. D.; Ellman, J. A. J. Org. Chem. 2014, 79, 8296-8303.

(10) (a) Elguero, J. In Comprehensive Heterocyclic Chemistry; Katrizky, A. R., Rees, C. W., Eds.; Pergamon Press: New York, 1984; Vol. 4, p 167. (b) Smalley, R. K. In Houben-Weyl Methods of Molecular Transformations: Hetarenes and Related Transformations; Schauman, E., Ed.; George Thieme Verlag: Stuggart, Germany, 2002; Vol. 11, p 348. (c) Boduszek, B.; Halama, A.; Zon, J. Tetrahedron 1997, 53, 1139911410 .

(11) Katritzky, A. R.; Wang, Z.; Hall, C. D.; Akhmedov, N. G. ARKIVOC 2003, 49-58.

(12) Chauhan, J.; Fletcher, S. Tetrahedron Lett. 2012, 53, 4951-4954.

(13) Bellamy, F. D.; Ou, K. Tetrahedron Lett. 1984, 25, 839-842.

(14) Nord, F. F. Ber. Dtsch. Chem. Ges. B 1919, 52, 1705-1712.

(15) Tokoroyama, T.; Kubota, T. Tetrahedron 1970, 26, 1085-1090.

(16) Climent, M. J.; Corma, A.; Iborra, S.; Marti, L. ACS Catal. 2015, $5,157-166$.

(17) (a) Rylander, P. N.; Karpenko, I. M.; Pond, G. R. Ann. N. Y. Acad. Sci. 1970, 172, 266-275. (b) Pernoud, L.; Candy, J. P.; Didillon, B.; Jacquot, R.; Basset, J. M. Stud. Surf. Sci. Catal. 2000, 130, 20572062. (c) Tamura, M.; Kon, K.; Satsuma, A.; Shimizu, K. ACS Catal. 2012, 2, 1904-1909.

(18) Cisneros, L.; Serna, P.; Corma, A. Angew. Chem. 2014, 126, 9460-9464.

(19) Boymans, E. H.; Witte, P. T.; Vogt, D. Catal. Sci. Technol. 2015, 5, 176-183.

(20) (a) Corma, A.; Concepcion, P.; Serna, P. Angew. Chem., Int. Ed. 2007, 46, 7266-7259. (b) Boronat, M.; Concepcion, P.; Corma, A.; Gonzalez, S.; Illas, F.; Serna, P. J. Am. Chem. Soc. 2007, 129, 1623016237.

(21) Combita, D.; Concepcion, P.; Corma, A. J. Catal. 2014, 311, $339-349$.

(22) Aramendía, M. A.; Benítez, J. A.; Borau, V.; Jiménez, C.; Marinas, J. M.; Ruiz, J. R.; Urbano, F. J. Colloids and Surfaces A: Physicochem. Colloids Surf., A 2000, 168, 27-33.

(23) Finney, E. E.; Finke, R. G. Inorg. Chim. Acta 2006, 359, 28792887.

(24) Corma, A.; Iborra, S. Adv. Catal. 2006, 49, 239-302. 